\title{
Tendencias en el cine expandido contemporáneo
}

\section{Massara, Gisela; Sabeckis, Camila; Vallazza, Eleonora [ver currículum del autor, docente de la Facultad de Diseño y Comunicación]}

\section{Resumen:}

El término "cine expandido" fue popularizado por Gene Youngblood en su libro Expanded cinema (1970), en el cual el autor señala los cambios que la expansión tecnológica, incluido el cine, pueden producir en la percepción y la conciencia, y en el cine mismo. El presente ensayo tiene como finalidad indagar en las producciones artísticas que se han desarrollado en las últimas décadas en Europa y Latinoamérica, en un contexto en el cual el auge de los avances tecnológicos está cambiando de manera sustancial la manera de producir films y de visualizarlos, modificándose de esta forma la actitud del espectador frente a la obra.

\section{Cuadernos del Centro de Estudios de Diseño y Comunicación N N 66}

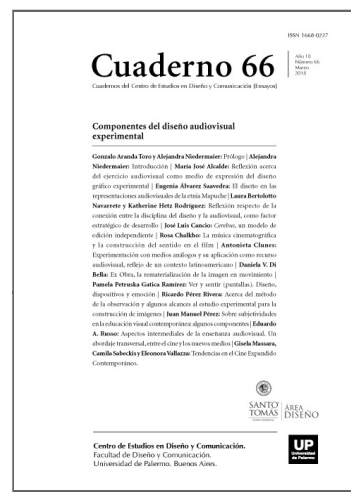

ISSN: 1668-0227

Componentes del

diseño audiovisual

experimental

Año XVIII, Marzo 2018, Buenos Aires, Argentina | 196 páginas

descargar PDF

ver índice de la publicación

Ver todos los libros de la publicación

compartir en Facebook

Esta obra está bajo una Licencia Creative Commons Atribución-NoComercialCompartirlgual 4.0 Internacional

Palabras clave: cine - expandido - experimental - vanguardia - video arte - avances tecnológicos - artes - films espectador.

$\left(^{*}\right)$ Doctoranda en Historia y Teoría de las Artes (UBA). Profesora y Licenciada en Artes, (UBA) Docente y crítica de arte. Desde el año 2009 se desarrolla como profesora en UADE y en la UP.

$\left.{ }^{(* *}\right)$ Licenciada y Profesora en Artes Combinadas (UBA), Crítica y docente, se especializa en tutorías de proyectos de graduación.

$\left.{ }^{* * *}\right)$ Especialista Superior en Gestión Cutltural (Fundación Konex). Licenciada y Profesora en Artes UBA). Investigadora, crítica y docente en UADE y en la UP.

Introducción

Desde el comienzo del Siglo XXI los avances en materia de ciencia y tecnología han sido considerablemente notables respecto de lo que fue el siglo anterior. El mundo en el que vivimos ha cambiado de manera vertiginosa 
en la última década, los avances en materia de comunicación han revolucionado la vida cotidiana y han cambiado de forma radical la industria del entretenimiento incluida la cinematográfica, modificándose substancialmente los procesos productivos al mismo tiempo que los nuevos dispositivos audiovisuales modifican los hábitos de los espectadores que ya no necesitan encerrarse en una sala oscura con pantalla gigante para ver un film, sino que pueden hacerlo en dispositivos portátiles y en cualquier ámbito que lo deseen.

Desde sus primeros pasos, allá por 1895, y a lo largo de más de un siglo, el cine se ha ido renovando de la mano de los avances tecnológicos, intentando perfeccionar su arte y alcanzar cada vez una mayor impresión de realidad. El sonido, el color, las tres dimensiones y la pantalla panorámica, fueron algunos de los avances más destacados del siglo XX en el campo cinematográfico, los cuales permitieron que el cine siguiera avanzando en su intención de reproducir con mayor fidelidad la realidad y competir asimismo con los nuevos inventos como la TV, el cable, los reproductores de video, etc., que desde mitad de siglo pasado han amenazado la continuidad de la industria debido a la merma que a partir de estos inventos se produjo en la asistencia de público a las salas de exhibición.

En la época actual, pasada la primera década del siglo XXI, los avances tecnológicos siguen en auge y cada vez más amenazan la continuidad de la industria cinematográfica tal como fue concebida por los pioneros hace ya un siglo. Aunque es cierto que la estructura de la misma ya había ido cambiando a mitad de 1900 con la caída del sistema de estudios y el auge del cine de autor en los 60', nunca como en la actualidad la industria y el cine en sí mismo, concebido como una serie de imágenes en movimiento captadas por una máquina y proyectadas en una sala de exhibición a oscuras, han sufrido un embate que está cambiando radicalmente la manera en que se realiza una película y en que es visualizada por el espectador. La cámara tomavistas y el celuloide son hoy parte del pasado, y el reducto cerrado de la sala oscura donde el espectador se sentaba a contemplar un film es hoy sólo una posibilidad más entre otras opciones: televisores, computadoras, tablets, celulares, etc. Es en este contexto de grandes avances tecnológicos que resurge cada vez con más ímpetu la idea de un cine que vaya más allá de la pantalla, que expanda sus posibilidades de proyección, cambiando de forma radical la forma de percibir del espectador y que a su vez se combine con otras artes posibilitando una experiencia estética más abarcativa, que saque al público de su rol pasivo y le permita encarar una actitud activa frente a la obra que está contemplando.

Este planteo de un cine que expanda sus fronteras hibridándose con otras artes no es nuevo, tiene su origen en los años 60 en lo que se ha denominado cine expandido. El cineasta experimental norteamericano Stan Van Der Beek fue quien acuñó el término en 1966, para denominar aquellas producciones donde se multiplicaban las pantallas de proyección y se transformaba el lugar de exposición, fusionando el cine con otras artes, deconstruyendo el lenguaje cinematográfico, y en las cuales se buscaba exaltar la experiencia sensorial, ya que el espectador no tiene un punto fijo de visualización sino que se mueve por el interior de las imágenes proyectadas. El término fue popularizado por Gene Youngblood en su libro Expanded cinema (1970), en el cual el autor señala los cambios que la expansión tecnológica, incluido el cine, pueden producir en la percepción y la conciencia, y en el cine mismo, "el cine expandido no es una película en absoluto: tal como la vida, es un proceso de transformación, el viaje histórico en curso para manifestar su conciencia fuera de su mente, frente a sus ojos" (Youngblood 1970). Para el autor la expansión de las tecnologías produciría una revolución cultural permitiendo un acceso más democrático a los medios de comunicación y la liberación del espectador de los medios masivos, permitiéndole abrir su mente y conformar una sociedad más justa. Youngblood aborda de esta manera el cine expandido como la expansión de la conciencia a través de la expansión de la tecnología. 
El cine expandido entonces incluiría a aquellas producciones que transgreden los cánones del cine comercial y los postulados narrativos convencionales, buscando generar una experiencia movilizadora en el espectador, rompiendo generalmente con la linealidad del relato y articulando las imágenes de forma de producir en el público una vivencia enriquecedora. En este punto la definición se acerca al cine experimental, haciéndose difícil en muchos casos poder encasillar una obra dentro de alguno de los dos conceptos. El cine experimental se define generalmente por aquello a lo que no pertenece, por lo que lo diferencia del cine canónico, comercial: no es ficción, no es documental, no puede encasillarse dentro de un género o formato determinado. En contraposición con el cine industrial el cine experimental se caracteriza por su falta de linealidad narrativa: como su nombre lo indica experimenta con el material audiovisual en busca de un lenguaje propio, es un cine personal, en el cual el cineasta participa de todas las instancias creativas: guión, cámara, sonido, edición, etc. Es un cine que dialoga con otras ramas del arte -pintura, poesía, literatura, fotografía, teatro, danza, etc.nutriéndose de estas, por eso en la actualidad forma parte de las exposiciones tradicionales de los museos. En este sentido, ya desde los años 60 han comenzado a surgir en distintas partes del mundo propuestas artísticas que es posible enmarcarlas dentro de esta caracterización de cine experimental, o expandido, obras que plantean una ruptura con el cine comercial y que desde un comienzo, al igual que este, han recurrido a las nuevas tecnologías para su desarrollo. Es por eso que en las últimas décadas este tipo de cine ha vivido un gran auge gracias a las nuevas posibilidades de producción y de exhibición que permiten los nuevos avances en materia de tecnología digital y audiovisual.

A diferencia de lo que sucede con el cine industrial/comercial, donde es posible aunar las obras de acuerdo al género, período histórico o nacionalidad, en el caso del cine experimental nos hallamos más cerca de lo que en cine se considera "cine de autor", ya que las obras son absolutamente personales, y reflejan en gran medida la subjetividad del autor, sus sentimientos y su percepción del mundo que lo rodea. Lo que generalmente tienen en común los distintos artistas que se dedican al cine experimental ó expandido en la actualidad es el hecho de provenir de distintas disciplinas artísticas y de utilizar el video como un medio de expresión en el cuál convergen diversas disciplinas artísticas como pintura, poesía, danza, literatura, etc. y donde las nuevas tecnologías juegan un papel fundamental.

\section{El cine expandido en Europa}

En el caso de Europa el panorama actual es muy amplio, es posible encontrar una gran variedad de propuestas que pueden englobarse dentro de este tipo de cine no comercial, que se funde con otras artes y ocupa un lugar importante dentro de la programación de algunos de los museos más importantes del continente. A continuación intentaremos trazar un panorama de lo más destacado de lo que se viene haciendo en materia de cine experimental/expandido en esta parte del mundo, a través de una selección de obras y artistas que se han destacado en el ámbito de este arte.

\section{Tacita Dean}

Es una de las artistas más destacadas del cine experimental europeo de las últimas décadas. Nacida en Cannterbury, Gran Bretaña en 1965, desde el año 2000 vive en Berlín. Dean estudió en la Falmouth School of Art de Cornualles y completó su formación en la Slade School of Fine Art de Londres, especializándose siempre en pintura. En la última década, Dean ha llevado las posibilidades de las películas más allá de las salas de cine y sus films se han mostrado en los museos y galerías más importantes de todo el mundo, donde se ha valido de 
la utilización de proyectores de $16 \mathrm{~mm}$. A lo largo de su carrera como artista visual ha filmado más de cuarenta películas en formato $16 \mathrm{~mm}$, entre ellas se destacan los retratos fílmicos de los artistas Mario Merz, CyTwombly, Claes Oldenburg, del reconocido coreógrafo Merce Cunningham o del poeta y traductor Michael Hamburger. Trabaja fundamentalmente con material fílmico, además de utilizar una gran variedad de medios, incluyendo dibujos (sobre papel, pizarra, magnéticos o de alabastro), fotografías y sonido. "Ciertamente, la obra de Tacita Dean congrega esos tres elementos fundamentales: el visible, el sonoro y el narrativo, sin que podamos concederle preeminencia a alguno de ellos en particular". (Navarro, 2006)

Su obra ha sido premiada en varias oportunidades y ha sido expuesta internacionalmente en instituciones como el Schaulager, Basilea (2006), New Museum, Nueva York (2008), la Tate Modern, Londres (2011), el Museo Nacional Centro de Arte Reina Sofía, España (2010), y el Museo Hirshhorn y Jardín de Esculturas, Washington, DC (2001). Dean es una defensora acérrima del soporte fílmico. Empezó filmando con una cámara Standard 8 continuó con una Super 8, y finalmente se quedó con la película de $16 \mathrm{~mm}$ que es la que usa en la actualidad. Sus películas se hallan en el extremo opuesto de la concepción del cine comercial o hollywoodense, se caracterizan por tener "tomas extremadamente largas que, más allá de perseguir una acción, lo que hacen es contemplar la auténtica apariencia del mundo sin adulterarla, un paseo por lo cotidiano en su propio tempo". (Santana, 2013) Dean tiene un gran interés por documentar el paso del tiempo, en sus films explora la relación entre el tiempo, el espacio y el movimiento como testigos de los acontecimientos históricos y de la memoria colectiva o individual.

En 2011 con su obra Film, expuesta en la Sala de Turbinas de la Tate, Tacita Dean realizó una suerte de homenaje al formato fílmico, manifestando con su trabajo su oposición a la desaparición de este material en manos del digital. En la oscuridad, como si estuviera en un cine, el espectador contempla una pantalla vertical en forma de película, con perforaciones en los lados incluidas, por la que durante 11 minutos verá circular todo tipo de imágenes: un sol brillante, el mar, un ojo, una chimenea industrial... se suceden en la pantalla reconstruyendo las creaciones que ha aportado el séptimo arte desde sus orí- genes. "Dean pintó, modificó e intervino los fotogramas con el objetivo de generar una experiencia única al espectador, que era así testigo de un trabajo audiovisual monumental realizado de forma artesanal"(Santos, 2015). A propósito de Film, Tacita Dean afirma lo siguiente:

En celuloide se trabaja con una transición que no existe en lo digital (...) la tecnología que controla la luminosidad y el contraste en nuestros sistemas digitales de grabación, no es aún capaz de captar matices que sí se registran en el sistema analógico. (...) El celuloide y lo digital son técnicas diferentes y producen cines diferentes. (2011)

\section{Jacques Perconte}

Nacido en Grenoble, Francia en 1974, Jacques Perconte es uno de los artistas multimedia más destacados en Francia en las últimas décadas. Utiliza los nuevos medios digitales para realizar sus creaciones, y es considerado uno de los pioneros en Francia en lo que se conoce como internet art. Jacques hizo sus primeras obras con internet y video arte, en 1995 realizó sus primeras películas, y su primer obra en Internet en 1996. El sitio web technart. net es el núcleo de su trabajo, mostrando todas sus actividades (notas, artículos, presentaciones, etc.). Suele trabajar con otros artistas como Michel Herreria (pintor), Didier Arnaudet (poeta), Marc Em (músico) y Hugo Verlinde (cineasta), entre otros. Su obra explora el cuerpo, el paisaje y el color a 
través de soportes digitales, dándole al arte digital una nueva dimensión pictórica, sus paisajes realizados en formato digital son cómo pinturas en movimiento, Perconte utiliza la tecnología como un nuevo medio artístico que puede ser estéticamente tan rico como cualquier otro del arte clásico.

El trabajo de Perconte se desenvuelve en torno a la noción de cambio, de viaje, de movimiento, esto puede apreciarse, por ejemplo, en una serie de pequeños videos (ensayos) que se titulan París, "sans titre" (2008), en los que se combinan imagen en movimiento con distorsión temporal, el desfilar de las imágenes, su ritmo, la variación de los colores, de los trazos y de los puntos que las componen, otorgan musicalidad a sus imágenes aún cuando no poseen sonido, aún careciendo de éste, sus obras son capaces de producir un efecto musical al contemplarlas.

Isabel Pérez del Pulgar

Videasta española que ha trabajado intensamente en sus obras el tema de la construcción de la subjetividad y la dualidad entre cuerpo y mente. Licenciada en Geografía e Historia del Arte en la Universidad de Granada, ha realizado también estudios sobre color, pintura y dibujo, artes gráficas y cursos sobre diseño y arte digital en la escuela de Artes de Granada. Trabajó durante varios años en las distintas disciplinas y técnicas plásticas, y luego se dedicó a la realización en video y la fotografía. Considera al vídeo un medio expresivo completo a partir del cual es posible indagar e investigar, dado que permite combinar el movimiento y el sonido con una visión pictórica. Sus trabajos no son concebidos individualmente sino como una continuidad y se dividen en series y en proyectos concretos. En Ossum (2014), video performance presentada en el Festival internacional de Video Arte de Madrid (IVAHM), la artista reflexiona sobre la dualidad existente entre el cuerpo y la mente y las contradicciones que se producen entre la conciencia del sujeto y la realidad externa que lo construye como elemento productivo y consumista:

El ser humano a lo largo de la historia se ha entendido como una realidad dual en lo que se refiere a mentecuerpo (...). Conceptualmente en la obra se plantea la relación existente entre el cuerpo como elemento orgánico y sus diversas realidades. Realidades fracturadas a modo de espejos en los que se refleja la imagen subjetiva. Subjetividad dependiente de la percepción individual, de la propia naturaleza frágil y efímera de la estructura orgánica que arma el cuerpo, y la comunicación establecida de manera directa con la conciencia (...). El cuerpo sometido a tensiones contradictorias y enfrentadas, entre una realidad que lo construye como elemento productivo y consumista, y la propia conciencia y creencia de lo que se es como ser humano relacionado con el entorno. (Perez del Pulgar, 2015)

\section{Abraham Hurtado}

Nació en el año 1972 en la ciudad de Murcia, España. Es licenciado en Artes Escénicas, coreógrafo, performer y artista visual. Trabajó con diversas compañías de teatro y danza, entre ellas La Fura dels Baus. Desde 2005 vive y trabaja en Berlín. En sus performances e instalaciones y videos Hurtado reflexiona sobre el estado del cuerpo a causa del sistema de vida moderno en el que se ve inmerso el individuo en las sociedades avanzadas, muchas de estas performances son grabadas y luego editadas convirtiéndose así en piezas de video que es posible visualizar en la web. 
Dirige desde el año 2006 la plataforma AADK (Arquitectura Actual de la Cultura) conformada por un grupo de artistas residentes en Berlín que idean proyectos de diferentes disciplinas artísticas: performance, instalación, vídeo arte, música, literatura, etc. Han presentado sus trabajos en más de 25 ciudades europeas, en México y EE.UU. AADK tiene una sede en España en el Centro Negra (Murcia), en este a partir de la creación y la investigación desarrolla proyectos artísticos en el ámbito rural.

En 2009 Hurtado estrenó una instalación y performance denominada Die Korper Ohne Uns, El cuerpo sin nosotros, a partir cuyas grabaciones editó un video que actualmente puede verse en distintas páginas de internet, igual que muchas de sus performances e instalaciones:

La propuesta, sobre la pérdida, la alucinación, la fantasía y el cuerpo inerte entre el espacio vivo-muerto, marca la individualidad como estado, la identidad como pérdida, la comunicación como salida. La pieza está pensada para tres personas solitarias y dos esculturas-cuerpo. A través del encuentro en el mismo espacio se crearán situaciones coreográficas y visuales llegando, sólo al final de ese encuentro, a una historia de ficción construida desde el puro movimiento. El cuerpo como instrumento de transmisión emocional y el movimiento que genera lo convierten en el auténtico protagonista en una propuesta carente de teatralidad. (Dancebox, 2009)

Esta obra como la mayoría de las performances, instalaciones y videos del autor hace hincapié en el tema del cuerpo, la pérdida de la individualidad y la soledad del individuo en la sociedad de consumo actual y la necesidad de comunicarse para encontrar una salida a esta situación que lo frustra.

Hito Steyerl

Nació en 1966 en Múnich, Alemania y se doctoró en Filosofía en la Universidad de Viena y como profesora de New Art Media en la Universidad de Berlín. Se dedica a la realización de cine y video documental de ensayo, media art y videoinstalación además de escribir ensayos críticos y dictar conferencias sobre temáticas como la militarización, la migración, la globalización cultural, el feminismo o la imagen política, entre otros, y se interesa especialmente por la forma en que las imágenes circulan y son difundidas sin control mediante las nuevas tecnologías digitales. Su trabajo se centra en la noción de que las tecnologías y la forma en que estas hacen circular las imágenes han tenido un alto impacto en la cultura, la economía y la subjetividad misma. Inge Stache, Curadora de programación cultural y de la Cinemateca del Instituto Goethe en Buenos Aires analiza la obra de la artista de la siguiente manera:

En su conjunto, los trabajos de Steyerl actualizan el análisis crítico del lenguaje de la imagen desde el punto de vista de una generación conectada a través de las redes digitales: retoman el lenguaje dominante de los medios masivos y, con humor refinado, lo desarman a partir de sus propias contradicciones para, luego, complementarlo con reflexiones que impulsan al espectador a nuevas lecturas reveladoras. (2014)

El humor es un recurso habitual en sus videos, su intención es analizar como la manera en que hoy circulan las imágenes y el modo en que son consumidas determina la forms en que las personas se comunican.

El cine expandido en Latinoamérica

Según Bernini, docente e investigador argentino, autor del prólogo de la edición de la Untref del paradigmático libro de Youngblood Cine Expandido, este concepto en realidad no se circunscribe al lenguaje cinematográfico, 
sino que apunta en última instancia a una expansión de la conciencia en la nueva era que, en su momento, el cine, en su forma experimental, permitió y que los nuevos medios tecnológicos (computadora, televisión y video) continúan y continuarán en un proceso indefinido e irreversible. Esa expansión de la conciencia humana a través de una democratización de las tecnologías de la comunicación debería sustentarse en una contracultura -un mundo cuyos significados, valores y definiciones de realidad sean exactamente contrarios a aquellos de la cultura dominante- y en un cambio de mentalidad que tenga la capacidad de derrumbar el control social.

El contexto sociopolítico de Latinoamérica en los '60, cuando comienza a gestarse el concepto de cine expandido y experimental, marcó y continúa haciéndolo, las distintas direcciones que tomaron los artistas visuales de la época. En relación al caso de Argentina, podemos encontrar varios casos paradigmáticos. Las autoras Alejandra Torres y Clara Garavelli en el ensayo ¿Qué es lo experimental del cine y video experimental argentino? (IMAGOFAGIA n 9 2014), parten de la ambigüedad del propio término "experimental", marcando cómo desde sus comienzos (por la década del '50 en EEUU) aquel cine denominado como tal no era más que un cine que no podía ser definido de otra forma, porque no era ficción ni documental. Sin embargo las autoras rescatan la importancia de investigar sobre el cine experimental partiendo de un concepto rescatado por uno de los autores y teóricos clásicos del cine, Jacques Aumont. El mismo, resalta la importancia del cine experimental (no narrativo), por las influencias permanentes que éste influye sobre el cine narrativo (Aumont, 1983, pp. 89147). Muchas veces, como si no se tratara de cine, las investigaciones dedicadas al "cine argentino" se focalizan en el cine clásico, narrativo, industrial, hegemónico. Otra autora que ha investigado sobre el tema del cine experimental en Argentina es Brenda Salama. En su ensayo "El cine experimental: entre el experimento y la experiencia. Las películas de Sergio Subero, Sergio Brauer y Mario Bocchicchio" (IMAGOFAGIA n 9, 2014) plantea la hipótesis de que el cine en su forma experimental en lugar de representar, produce, presenta, expande la realidad. Para fundamentarla toma el ejemplo de la obra de los realizadores argentinos Sergio Subero, Sergio Brauer y Mario Bocchicchio, quienes vinculan la experimentación cinematográfica con la experiencia del espectador. De esta forma se vincula con el concepto de cine expandido desarrollado por Youngblood en relación al cine experimental del EEUU. Siguiendo los planteos teóricos de ambos la investigación dialoga conceptualmente con esta hipótesis que relaciona al cine experimental con el concepto de cine expandido. El cine experimental debe ser entendido, ante todo, como un arte personal, en tanto que implica un modo singular de vincular el uso racional de la técnica (experimento) con las condiciones vitales que lo hacen posible (experiencia), cuyo fin último es la transformación de la visión, en sentido amplio, que tenemos de la realidad. (Salama 2014)

Otro antecedente que analiza el cine expandido en argentina es el ensayo de Rodrigo Alonso "Fuera de las formas del cine: Experiencias de Cine Expandido en Argentina". Alonso parte de una conceptualización desarrollada por Youngblood al definir:

Denominaremos cine expandido, uno de los antecedentes más importantes de las instalaciones espaciales de imágenes que iban a popularizar las video instalaciones (...). Por un lado, algunos artistas exaltaron el aspecto sensorial de la relación entre la imagen y el espectador, generalmente influenciados por la recuperación de lo sensorial que siguió al movimiento hippie. En el extremo opuesto, artistas enrolados en la incipiente tendencia conceptual, destacaron el aspecto informativo de la imagen, su capacidad para constituirse en comentario sobre la realidad, y su estatuto de intermediario entre ésta y el espectador. (Alonso, 2001) 
Partiendo de esta hipótesis de trabajo es cómo el autor desarrolla las dos vertientes que se dieron también en la cinematografía argentina: la vertiente sensorial y la conceptual. Nombra como pionera de la vertiente sensorial a Marta Minujín. Luego desarrolla la obra de Oscar Bony como uno de los pioneros de la vertiente conceptual y David Lamelas que la utiliza para analizar por igual el espacio de una galería de arte y el propio modelo narrativo cinematográfico en Film Script (Londres, 1972). Los principales referentes argentinos de la vertiente sensorial de la década del '70, en relación a la experimentación formal con el lenguaje cinematográfico son: Marie-Louise Alemann, Narcisa Hirsch, Claudio Caldini, Horacio Vallereggio, Jorge Honik, Silvestre Byrón, Juan Villola, y Adrián Tubio.

El cine expandido latinoamericano en la actualidad

Para plantear un claro panorama sobre las diferentes tendencias dentro de la experimentación audiovisual latinoamericana, resulta interesante, analizar programaciones de algunos eventos como la BIM (Bienal de Imagen en Movimiento), realizada recientemente en la ciudad de Bs. As. En la misma, el visitante podía encontrarse frente a algunos prestigiosos artistas provenientes del continente americano. En la edición 2014, por ejemplo, se programó un ciclo curado por José Carlos Mariátegui denominada "Video arte peruano del último quinquenio, una mirada desde las artes visuales". A finales de los años noventa, el video en el Perú no se consideraba aún parte de las artes visuales establecidas, se mantenía al margen. Aquella amplitud no solo se evidenciaba por la variedad y el grado de experimentación en los trabajos realizados, sino también por la formación multidisciplinar de las personas vinculadas a su producción, que en muchos casos no tenían estudios artísticos formales. En la segunda década del siglo XXI, el video peruano ha sido legitimado por galerías y crítica especializada.

Muchos de estos artistas producen video como parte de un repertorio mayor de formatos, como la fotografía, la instalación o la escultura. Enmarcar a estos creadores como artistas de video exclusivamente puede ser complicado ya que, en muchos casos, su obra audiovisual se complementa e influencia con otros medios y viceversa. Los artistas peruanos que formaron parte de esta programación fueron: Ricardo Yui proviene de la fotografía y ha venido experimentando con el video como una forma de documentar con mayor riqueza y detalle algunos procesos socioculturales urbanos que son parte de la realidad en la que vivimos. Por otro lado, Katherine Fiedler produce breves videos que juegan con el hiperrealismo fotográfico, que, como si fuesen argumentos de cuentos de hadas, incrementan la dosis de narrativa de sus historias. Maya Watanabe es una artista que ha venido produciendo consistentemente, desde hace casi una década, obra exclusivamente en video. Escenarios es su primer conjunto de obras con imágenes filmadas de forma panorámica en 360 grados. Mediante una técnica de animación artesanal, Marco Pando viene produciendo lienzos de novo a partir de conjuntos de películas de cine pegadas entre sí. Esto resulta en animaciones en las que los personajes dibujados pasan por situaciones fantásticas en el marco de problemáticas sociales que forman parte de nuestras alucinaciones cotidianas. Desde sus inicios como autor, David Zink Yi ha venido desarrollando obras en video y videoinstalación dentro de un imaginario de composición visual y sonora. El ritmo de sus imágenes se relaciona de forma sustancial con el sonido y genera potentes composiciones audiovisuales. Ximena Garrido-Lecca es una artista multidisciplinaria y utiliza el video en sus proyectos de instalación complementando el proceso de investigación que demanda la producción de su obra. Sus videos se convierten así en un recurso etnográficovisual de documentación. La selección concluye con la obra de Elena Damiani, quien viene trabajando alrededor de la persistencia de la memoria mediante la transformación de material encontrado. 
Una recurrencia que se da en el ámbito de la experimentación audiovisual, desde sus comienzos en los '60 hasta la actualidad en Latinoamérica, es la cita constante a problemáticas sociales y políticas de cada contexto. En algunos casos esta alusión es más literal que en otras, pero en muchos artistas podemos observar una necesidad de ir más allá de una experimentación formal, para llevar la obra a un plano de confrontación y reflexión para el espectador.

Otro caso interesante, presente en la última programación de la BIM, fue el del grupo CRÁTER (Venezuela España). Presentaron un programa doble de cine expandido en el que la imagen física se sustituye por la incandescencia. Las intermitencias lumínica y sonora provocadas por los distintos proyectores de $16 \mathrm{~mm}$. y Super 8 llevan al espectador a un límite perceptivo. A partir de una propuesta formal y conceptual sobre los inicios del cine, Luis Macías y Adriana Vila intervienen la pantalla y el espacio otorgando protagonismo a los elementos básicos de la proyección cinematográfica. Al manipular el proyector y la obturación de la luz, se crean coreografías lumínicas que remiten al cine primitivo jugando con los sistemas de percepción e ilusión óptica e ironizando sobre los mecanismos de la visión estereoscópica.

Actualmente en la Ciudad de Bs. As., se da una muestra del video artista argentino Andrés Denegri, esta instalación denominada Clamor agrupa tres obras: Éramos esperados (2012), Éramos esperados (16mm) (2013) y Éramos esperados (35mm) (2015). El montaje de la misma consta de dos proyectores de cine enfrentados que disparan imágenes que son capturadas por una pantalla que se encuentra entre ambos. Una proyección es la filmación que el relato corriente presenta como la primera de la historia del cine: Obreros saliendo de la fábrica, de Louis Lumière; la otra hace referencia a la primera filmación en territorio nacional: "La bandera argentina", de Eugenio Py. Lo que diferencia a las tres obras es el soporte cinematográfico con el que está realizada cada una, los proyectores correspondientes, las estructuras con las que se sostienen estos proyectores y que conducen el paso de la película y, sobre todo, sus tamaños. Una gran escultura cinética, donde las imágenes proyectadas se integran al valor estético de las máquinas cinematográficas y de la misma película de cine que sale de ellas para recorrer la sala de un extremo al otro. Andrés Denegri, tiene una amplia trayectoria en la experimentación audiovisual, como también en el campo de la investigación y la docencia. El objetivo de esta instalación, es precisamente reflexionar sobre la evolución de los distintos soportes cinematográficos ampliando la experiencia perceptiva del espectador, que encuentra una multiplicidad de pantallas y formatos, como parte de una misma obra.

Otro caso interesante para reflexionar sobre las transformaciones que las nuevas tecnologías han generado en el campo audiovisual, es el denominado "Documental Expandido". El autor de una tesis doctoral, Gabriel Sucari Jabbaz, ha desarrollado ampliamente este nuevo género cuya conceptualización puede aplicarse a varias experiencias en la región latinoamericana. Define al mismo como resultado de un nuevo paradigma en el que la representación documental contemporánea amplia el cuadro bidimensional de la TV o el cine, a partir de las nuevas tecnologías, se genera una multiplicidad narrativa y permite al espectador un recorrido aleatorio por la información. El documental expandido "propone nuevas formas de representación que trasciende las características de un medio específico, este documental post media produce un modelo en donde se aúnan el cine, el video, la fotografía, el texto, la informática y la instalación”. (Scari Jabbaz, 2009)

Un caso que representa claramente este tipo de representación documental expandida es el WebDoc. El mismo consiste en un nuevo formato de periodismo que está empezando a aparecer, un género basado en el fotorreportaje, que incorpora a un contenido documental, imágenes, videos, audio y herramientas multimedia. Es 
una oferta de contenidos nativa de la Web, que busca conquistar a los usuarios de dispositivos móviles como los tablet y smartphone. Las historias son contadas a través de la combinación de diferentes medios, utilizando las herramientas y funciones específicas de la red.

Es un sistema interactivo documental, multiformato, concebido y enriquecido con recursos audiovisuales y producido para su difusión vía Internet. Se trata de una herramienta de productos multimedia que combina texto, foto, video, sonido y animación de manera interactiva, didáctica y educativa. Su función principal es difundir información y captar el interés de las personas que no tienen un hábito por la lectura y que se sienten a gusto con la Internet como fuente de información creíble, frente a las noticias de la televisión y la prensa en general.

En Brasil se generó, por ejemplo, un web doc sobre graffiteros de la ciudad de San Pablo, la url es http://www.webdocgraffiti.com.br/. Como su formato lo indica es una documental interactivo sobre el arte urbano en la capital paulista. Cada mes se sube un nuevo episodio abordando temas, estilos colectivos y artistas diferentes. El usuario puede visualizar cada episodio en el orden deseado y de forma aleatoria de acuerdo a sus intereses. Por otro lado se plantea el recorrido audiovisual por un gráfico que representa el mapa de la ciudad con las calles y barrios intervenidas por los artistas. Para cerrar el foco puesto en la interactividad del espectador, es que en cada episodio el mismo puede dejar sus comentarios y reflexiones que a su vez generan un diálogo directo con los artistas.

Cine de exposición en la 29 Bienal de San Pablo

La 29 Bienal del año 2010 se presentó como un espacio de exhibición de varias propuestas audiovisuales. Algunas de ellas fueron concebidas por varios cineastas como Jean-Luc Godard, Steve McQueen, Chantal Akerman, Pedro Costa, entre otros. Varios son los escritos que reflexionan acerca del encuentro entre el arte contemporáneo (más específicamente su espacio de exhibición: museos, galerías) y el cine (en relación a la proyección y exhibición). Uno de los más importantes teóricos que abordó esta problemática fue JeanChristophe Royoux (1999) a partir del concepto "Cine de exposición". Cada vez es más frecuente que los museos incorporen prácticas audiovisuales dentro de su programación. Esta tendencia se ha incrementado a lo largo de estos últimos años. Los museos o galerías se presentan como posibilidad de la conformación de espacios de proyección. Royoux (1999) afirma que el cine de exposición es la “... confluencia inédita de ambos campos, se trata en todo caso de concebir la sintaxis de un dispositivo espacial que funciona por sí mismo, o que se aventura, como verdadera máquina de democraticidad". El traslado de la exhibición fuera de la sala obscura clásica abre la posibilidad de reconfigurar el lenguaje de lo cinematográfico. Algunos de los ejes del cine en cuánto a relato y tiempo se han modificado en su relación con los espacios dentro del museo o galería. La condición del espectador como vouyerista, no activo físicamente, altamente identificado con lo que acontece en la pantalla va a transformarse en un nuevo espectador. La concepción y construcción del relato muchas veces va a estar asignada a la recepción y no a la producción del mismo. Es decir se establece un feedback entre el artista y el espectador, y es en este proceso donde se da lugar el relato. De acuerdo con Royoux,

La transposición de un modelo cinematográfico al contexto de las artes plásticas -proyección de diapositivas, secuencias de imágenes, instalaciones de vídeo- con una serie de efectos específicos -abandono de la autonomía de la imagen, temporalización de la representación-, y aunque hablemos de un cine no-narrativo o anti-narrativo -en el sentido que ha devenido habitual el término, como opuesto a eso que, a partir de 1973, se 
denominará story art o narrative art- ha permitido en tiempos recientes la emergencia de nuevas modalidades de relato. (1999)

Estás nuevas modalidades están directamente relacionadas con el espectador. Es el propio cuerpo del espectador el que armará con su recorrido, transitando los múltiples espacios en los que se nos ofrece la obra, los posibles relatos que surjan de las imágenes. La narración no es un a priori en muchas de las obras, sino que se conforma con el devenir temporal y espacial del propio espectador. Philippe Dubois reflexionó sobre el cine de exposición en términos de "migración de dispositivos" (2011) a la relación entre el arte contemporá- neo y el cine. No se trata de proyectar una película, más allá que se use un proyector, sino que se quiebra con lo propio del cine, tal como lo conocíamos. Se pasa de una sala obscura que clausura el exterior, a un lugar con plena luz. "La sala obscura se presentaba como dispositivo de aislamiento, lugar cerrado, caverna, que establecía una relación bilateral" (Dubois, 2011). Es en este lugar donde están dadas las condiciones para que el espectador experimente una inmersión total con el espectáculo, conduciéndolo a una identificación con lo exhibido. Si bien la identificación se refiere a lo personal lo propio del cine es que es un hecho colectivo. La recepción está condicionada por lo colectivo. La inmersión en el cine está dada en el plano psíquico y no físico. El cine de exposición modifica la inmersión, la vuelve física. Aparece el cuerpo del espectador como eje fundamental de las obras. Harun Farocki (cineasta, República Checa) a partir de la video instalación Serious Games III: immersion [2009] expone esto "juegos" que fueron realizados para trabajarse como terapia para soldados que combatieron en la guerra de Irak. Realidad virtual y simulación computarizada conforman dentro del espacio posibles lecturas en la medida que el espectador decida que ver. Lo físico esta dado por la libertad de avanzar por los espacios e intersticios que son parte de la obra. La sala permanece abierta y dispuesta a ser atravesada, transitada. "Se deja la sala obscura para pasar al museo o galería. Es decir se pasa a otro dispositivo: el dispositivo museal" (Dubois, 2011). Al modificarse la exhibición y proyección de las obras nos dan algunos indicios de cierto agotamiento en las formas clá- sicas del cine. Específicamente en la recepción del mismo. ¿De qué manera el espectador contemporáneo inicia la búsqueda de otras formas de ver cine? Según Dominique Païni,

El museo ha sido una nueva vía para que el cine siguiera encontrando un público que ya no estaba dispuesto a aceptar el hecho de ir a ver películas de la misma forma que en el siglo XX. El público hoy ya no va a una sala de cine como iba antiguamente. El público ya no tiene ganas de ser cautivo, de estar capturado por el tiempo de una película. El cine hoy en día no puede conocer una sola forma de ser visto. (2010)

Este espectador conforma con sus recorridos nuevas lecturas en relación a la obra. La misma se presenta como lugar a ser explorado, alejándose de la mera contemplación. El espectador atraído por estímulos visuales y muchas veces sensoriales avanza en diversas direcciones para poder percibir la obra desde diferentes aristas. Estos nuevos lugares se han denominado como arquitecturas de recepción dentro de lo que se llamó "cine expandido". Estos espacios son altamente performativos e interactivos. Amar Kanwar (cineasta, Nueva Delhi) presentó la video instalación The Lightning Testimonies [2007] la cual cuenta con ocho proyectores donde dirigen la imagen a pantallas inmateriales. Cada una explora diversas historias de mujeres que padecieron violencia de género. El montaje estará a cargo del espectador con los recorridos que se instauren a partir de la búsqueda da cada uno. En este recorrido Dubois observa una especie de montaje construido por el espectador. "El desplazamiento del espectador como narrativa, como montaje horizontal" (2011). En cada recorrido se hace presente una decisión por parte del espectador donde va configurando de sentido a la obra. No hay un a priori de la narración, se da en el acto mismo de la exploración de la obra, se da en el espacio. Se crea un montaje a partir de los desplazamientos del espectador, muy por el contrario a la postura contemplativa que acontecía en la 
sala obscura. La invitación a recorrer los espacios esta relacionada con las diferentes pantallas y la cantidad de proyectores que se ubiquen en el espacio. Se puede observar una infinidad de combinaciones posibles en distintos tipos de pantallas, las hay: móviles, sólidas, invisibles (proyectadas en otro lugar), translúcidas, multipantallas.

El cine de exposición quiebra la noción de tiempo. Dubois diferenció "un tiempo libre en relación a un tiempo impuesto" (2011) En la sala de cine se impone el tiempo de la proyección clásica, el espectador no decide sobre el tiempo de la misma sino muy por el contrario el tiempo se le impone. En el caso de la exposición, el espectador cuenta con un tiempo libre en el cual es él quien decide la temporalidad de la obra. Las salas en galerías y museos permiten el libre acceso y la permanencia en la misma está dada por las elecciones que haga el espectador de acuerdo a su interés.

\section{Conclusión}

Para concluir sobre la evolución y tendencias del cine expandido en Latinoamérica, podemos reflexionar sobre un punto de partida en común con las experiencias contraculturales de la década del '60, que se dieron de forma simultánea en la región y en Estados Unidos y Europa. Tal vez, el punto en común de los experimentales audiovisuales latinoamericanos sea su permanente reflexión sobre el contexto socio político de cada país, algo que se generó en sus comienzos con el cine político como también en varios video artistas contemporáneos.

Por otro lado, el cine expandido, ha tenido un punto de inflexión en su desarrollo a partir de la irrupción de las nuevas tecnologías, que no solo transformaron la experiencia perceptiva del espectador sino también las estructuras narrativas tradicionales del cine documental y el cine de exposición, entre otros géneros.

\section{Bibliografía}

Alonso, R. (2001). Fuera de las formas del cine: Experiencias de Cine Expandido en Argentina, Presentado en: Segundas Jornadas Nacionales: El Cine y las Artes Audiovisuales. Enfoques Analíticos y Transdisciplinarios. EINCITED. Universidad de Buenos Aires. Archivo General de la Nación, Buenos Aires, 2001.

Altman, A. (Diciembre de 2009). Hito Steyer - NeuerBerlinerKunstverein. Frieze Magazine Nro. 127. Disponible en: http://www.frieze.com/issue/review/hito_steyerl

Caja Negra editora (2015). Los condenados de la pantalla, Hito Steyerl (2015). Recuperado el 22/08/2015 de http://www.cajanegraeditora.com.ar/libros/los-condenados-de-lapantalla-0-

Civale C. (14 de Noviembre de 2014). La muerte del cine. Página 12, Suplemento Las 12. Disponible en: http://www.pagina12.com.ar/diario/suplementos/las12/13-9300-2014- 11-16.html

Dance Box. The Körper OhneUns. Recuperado el 10/08/2015 de: http://dancebox.es/contiene lescenicas/2009/05/1818/ Dean, T. (2013). La vanguardia Cultura. Salvar el celuloide. http://www.lavanguardia.com/ cultura/20130828/54380779536/salvar-celuloide.html

Elder, M. D. (1932). TheMyth of Progress (en inglés). The British Journal of Medical Psychology, 1932, Vol. XII, p. 1. 
Erre que Erre Danza (2015). Hoogerman 2012. Recuperado el 20/08/2015 de: http://www. errequeerredanza.net/?p=1450\&lang=es

Hessler S. (2014). Lugar a dudas. La vitrina. KlaraLidén de Mith of progress (Moonwalk) Recuerado el 17/08/2015 de: http://www.lugaradudas.org/publicaciones/exhibiciones/2014_03_vitrina_klaraliden.pdf

Hurtado, A. (2013). Instituto Cervantes. IgnitionLab. Recuperado el 10/08/2015 de: http:// berlin.cervantes.es/FichasCultura/Ficha91269_57_1.htm

Jaques Perconte (2015). Recuperado el 10/08/2015 de http://www.jacquesperconte.com

La Ferla, J. (2008) Cine expandido o el cine después del cine, La Nación - ADN Cultura - 16 de Febrero de 2008.

Lech I. (2015) VIDEOsPAIN, Intineranciastransvisuales. Recuperado el 10/08/2015 de http:// issuu.com/publicacionesaecid/docs/videospain

Morey J. (2013). Sneo Danza. La Red. Abraham Hurtado: Cuerpo, conciencia y reacción. Recuperado el 12/08/2015 de: http://sneodanzalared.es/profiles/blogs/abraham-hurtadocuerpo-conciencia-reaccion

Navarro, M. (2006). SalonKritik. Tacita Dean, esquivar la ficción. Recuperado el 15/08/2015 de http://salonkritik.net/06-07/2006/08/tacita_dean_esquivar_la_ficcio.php

Noble, K. (Enero-Febrero 2011). KlaraLidén - Serpentine Gallery. Frieze Magazine Nro. 136. Disponible en: http://www.frieze.com/issue/review/klara-liden/ http:/Enreo-Feb 2011

Perez del Pulgar, I. (2015). IVAHAM. Ossum. Recuperado el 12/08/2015 de: http://ivahm. com/ossum-isabelperez-del-pulgar/ Païni, D. (2010, octubre). El cine expuesto (Revista Lumiere) [Video]. Recuperado de https:// vimeo.com/25887752

Espacio Fundación Telefónica (2011). Clase magistral de Philippe Dubois: Arte contemporá- neo: cine expuesto, móvil, transmitido. Material no publicado. Recuperado el 13 de mayo de 2015, https://www.youtube.com/watch? v=Wp3SpvJVH8s Royoux, J. C. (1999). Por un cine de exposición. Retomando algunos jalones históricos.

Acción Paralela \#5. Recuperado de: http://www.accpar.org/numero5/royoux.htm

Salama, B. (2014). "El cine experimental: entre el experimento y la experiencia. Las películas de Sergio Subero, Sergio Brauer y Mario Bocchicchio", IFOMAGIA n 9. Recuperado de file:///C:/Documents\%20and\%20Settings/Usuario/Mis\%20documentos/Downloads/ DialnetEICineExperimentalEntreEIExperimentoYLaExperiencia-4747105.pdf

Santos, J. (2015). Arte y Crítica.org. Tacita Dean, el último rayo verde. Recuperado el 15/08/2015 de: http://www.arteycritica.org/tacita-dean-el-ultimo-rayo-verde/

Sena Caires (2009). Arte digitais Blog. Jacques Perconte e a ilusão de continuidade. Recuperado el 10/08/2015 de: artes.ucp.pt/artesdigitais/?p=278 
Soucheyre, G. (Noviembre 2014). Bienal de la Imagen Movimiento. Recuerdos futuros. Recuperado el 15/08/2015 de: http://bim.com.ar/proyeccion-2014/?proyeccion=1815

Stache, I. (2014). Goethe Institut. Hito Steyerl en Buenos Aires. Recuperado el 15/08/2015 de: http://www.goethe.de/ins/ar/es/bue/ver.cfm?fuseaction=events.detail\&event_id=20439365

Torres A., Garavelli C. (2014). ¿Qué es lo experimental del cine y video experimental argentino?, IFOMAGIA n9. Recuperado de http://www.asaeca.org/imagofagia/sitio/index. php? option=com_content\&view=article\&id=400\%3Aique-es-lo-experimental-del-ciney-video-experimentalargentino\&catid=54\%3Anumero-9\&ltemid=169

Youngblood, G. (2012). Cine Expandido. Buenos Aires: Eduntref.

\section{Abstract:}

The term "expanded cinema" was popularized by Gene Youngblood in his book Expanded Cinema (1970) where the author points out the changes that technological expansion -including cinema- can produce in the perception, in the concience and in the cinema itself. This article aims to explore in the art productions that have been developed in the last decades in Europe and Latin America in a context where the raise of technological advances are changing in a substantial way both film production and film visualization producing a behavioral change in spectator attitude towards the film.

Key words: cinema - expanded - experimental - Vanguard - video art - technological advances - art - film spectator.

\section{Resumo:}

A expressão "cinema expandido" foi popularizada por Gene Youngblood no livro Expanded Cinema (1970), onde o autor expõe as mudanças que a expansão tecnológica, incluído o cinema, podem produzir na percepção e na consciência, e no mesmo cinema. Este ensaio tem como finalidade indagar nas produções artísticas que se desenvolveram nas últimas décadas na Europa e Latino-américa, num contexto onde o auge dos avanços tecnológicos está mudando substancialmente a maneira de produzir filmes e de visualiza- -los, mudando assim a atitude do espectador frente á obra.

Palavras chave:

cinema - expandido - experimental - vanguarda - vídeo arte - avanços tecnológicos - artes - filmes - espectador.

Tendencias en el cine expandido contemporáneo fue publicado de la página 157 a página172 en Cuadernos del Centro de Estudios de Diseño y Comunicación № 66 